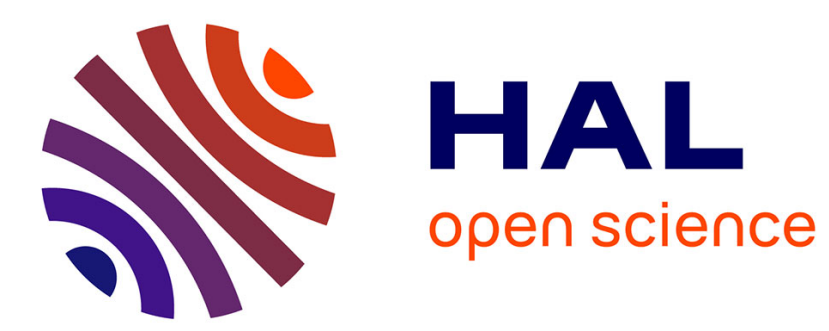

\title{
Fast fault identification in bipolar HVDC grids: a fault parameter estimation approach
}

Paul Verrax, Alberto Bertinato, Michel Kieffer, Bertrand Raison

\section{To cite this version:}

Paul Verrax, Alberto Bertinato, Michel Kieffer, Bertrand Raison. Fast fault identification in bipolar HVDC grids: a fault parameter estimation approach. IEEE Transactions on Power Delivery, 2022, 37 (1), pp.258-267. 10.1109/TPWRD.2021.3056876 . hal-03172421

\section{HAL Id: hal-03172421 \\ https://hal.science/hal-03172421}

Submitted on 17 Mar 2021

HAL is a multi-disciplinary open access archive for the deposit and dissemination of scientific research documents, whether they are published or not. The documents may come from teaching and research institutions in France or abroad, or from public or private research centers.
L'archive ouverte pluridisciplinaire HAL, est destinée au dépôt et à la diffusion de documents scientifiques de niveau recherche, publiés ou non, émanant des établissements d'enseignement et de recherche français ou étrangers, des laboratoires publics ou privés. 


\title{
Fast fault identification in bipolar HVDC grids: a fault parameter estimation approach
}

\author{
Paul Verrax, Alberto Bertinato, Michel Kieffer, Senior Member, IEEE, and Bertrand Raison, Senior Member, IEEE
}

\begin{abstract}
The protection of meshed HVDC grids requires the fast identification of faults affecting the transmission lines. Communication-based methods are thus not suited due to the transmission delays. Many approaches involving a model of the transient behavior of the faulty line have recently been proposed. Nevertheless, an accurate description of the traveling wave phenomenon in multi-conductor lines such as overhead lines requires complex computations ill-suited for fast fault identification.

This paper presents a single-ended fault identification algorithm using a closed-form parametric model of the fault transient behavior. The model combines physical and behavioral parts and depends explicitly on the parameters that characterize the fault, namely the fault distance and impedance. When a fault is suspected, the fault parameters are estimated so that the model fits best the received measurements. The confidence region of the estimated fault parameters is used to decide whether the protected line is actually faulty or not.

The proposed algorithm is tested on a 4 station grid simulated with EMTP-RV software. The method is able to identify the faulty line using a measurement window of less than $0.5 \mathrm{~ms}$. This allows ultra-fast fault clearing and can hence improve the overall reliability of future HVDC grids.
\end{abstract}

Index Terms-Protection, fault identification, modal analysis, parameter estimation, HVDC grids

\section{INTRODUCTION}

$\mathbf{T}$ HE rising share of renewable energy sources in the electric mix requires the increase of long distance transmission capacities [1]. The recourse to High Voltage Direct Current (HVDC) reduces the transmission losses and is required for non-synchronous zone interconnections or long distance underground links. Furthermore, the development of meshed HVDC (MTDC) grids to replace existing point-topoint links will increase the grid reliability and flexibility while decreasing the investment costs. Nevertheless, the operation, control, and protection of MTDC grids embedded in the existing high voltage $\mathrm{AC}$ network still rises a number of challenges [2]. Among those, the ability to selectivity clear

This work was carried out at the SuperGrid Institute, an institute for the energetic transition (ITE). It is supported by the French government under the frame of "Investissements d'avenir" program with grant reference number ANE-ITE-002-01.

P Verrax is with the Supergrid Institute, 23 rue Cyprian, 69100 Villeurbanne, France, e-mail: paul.verrax@supergrid-institute.com.

M Kieffer is with the L2S, Univ Paris-Sud, CNRS, CentraleSupelec, Univ Paris-Saclay, 91190 Gif-sur-Yvette, France, e-mail: michel.kieffer@12s.centralesupelec.fr.

A Bertinato is with the Supergrid Institute, 23 rue Cyprian, 69100 Villeurbanne, France, e-mail: alberto.bertinato@ supergrid-institute.com

B Raison is with the Univ. Grenoble Alpes, CNRS, Grenoble INP*, G2Elab, 38000 Grenoble, France (* Institute of Engineering Univ. Grenoble Alpes), e-mail: Bertrand.Raison@univ-grenoble-alpes.fr. the faults occurring on the transmission lines, i.e., by opening only the faulty line, is seen as particularly demanding. The fast rise of the current and the absence of current zero crossing make the disconnection of the faulty line an arduous task.

Each line is monitored by two relays at its extremities that control the opening of the breakers, also located at the end of the lines, see Figure 1 for an example of a four station meshed grid. DC reactors are generally placed at the end of each line to limit the rise of the current after a fault. For overhead line (OHL) based grids however, the current does not rise as fast as in cabled based grids. Consider for instance hybrid DC circuit breakers with breaking capabilities of $16 \mathrm{kA}$ in $2 \mathrm{~ms}$ [3] and a protection algorithm able to send the tripping orders in less than $0.5 \mathrm{~ms}$. The faulty line can thus be disconnected in $2.5 \mathrm{~ms}$ after the fault inception without having recourse to such inductances [4]. Omitting the DC reactors reduces the cost and footprint of the stations and is beneficial for the dynamical behavior of the grid [5]. Such stringent time constraints on the fault identification make the use of communication between distant relays not suitable. Consequently, the protection algorithm implemented at each relay must be able to distinguish the faults occurring on the line it monitors from the faults occurring elsewhere in the grid so that only the faulty line is disconnected. Thus, a singleended algorithm able to identify internal faults in less than $0.5 \mathrm{~ms}$ is an enabler for a fast selective fault clearing strategy.

Most existing techniques are based on the measurements of the current, voltage as well as their rate of change to detect and identify faults. By contrast, we focus here on model based approaches that employ a prediction of the voltage and current evolution after the fault occurrence. A fault affecting a transmission line generates traveling waves (TW) that propagate throughout the grid. The TW propagate at various speeds along the line which correspond to the speeds of different modes (e.g. ground and aerial). The surge arrival time difference between the different modes is analyzed in [6]. This time difference depends on the fault distance and is used to identify faults by comparison with the expected maximum time difference for internal faults. Nevertheless, the detection of the arrival times of the different modes may prove difficult, in particular for faults occurring close to a station. In the context of DC micro-grid, [7] proposes to estimate the fault distance and resistance using a simple RL model for the distribution lines. The confidence level of the estimated parameters as well as the value of the estimated fault distance are used to identify internal faults. The method in [7] shows good results on a cable-based micro-grid but the extension to an HVDC grid would require a different approach for modeling long distance transmission lines. The Bergeron's model is employed along 
with rational filters in [8] to describe the voltage and current at a fixed set-point along the line. The fault distance with respect to the set-point is then computed based on a simplified RL model. The distance protection principle is then applied, comparing the obtained distance with the pre-determined setpoint. The approach is able to differentiate faults occurring before and after the set-point but is only tested on point-topoint links. In addition, the required measurement window is $15 \mathrm{~ms}$ long which is not compliant with the fast fault clearing of the line.

We have proposed a single-ended fault identification algorithm in the case of a mono-conductor transmission line in [9]. This paper extends this approach to the more general case of overhead lines with multiple pole conductors. A particular effort is required to accurately model the propagation of the different modes along the transmission lines with relatively compact expressions. The behavioral approach to account for the ground effects in the mono-conductor case can not be directly applied as the different modes are affected unequally by the ground. Furthermore, the developed model must depend explicitly on the fault parameters and be adjustable to any fault cases affecting the protected line. When a fault is suspected at a relay, the unknown fault parameters (the fault resistance and distance) of the model are estimated using the received measurements. The estimated fault parameters and their confidence intervals are exploited to determine whether or not one has to consider that the fault actually occurred on the protected line. If an internal fault is identified, the line breaker is opened and a selective protection strategy is triggered.

A general overview of the proposed fault identification algorithm is presented in Section II. The DC fault modeling in multi-conductor transmission lines is detailed in Section III. Simulation results for the model are presented and compared with Electromagnetic-transient (EMT) [10] data in Section IV. The proposed fault identification algorithm is tested and compared with an existing method in Section V.

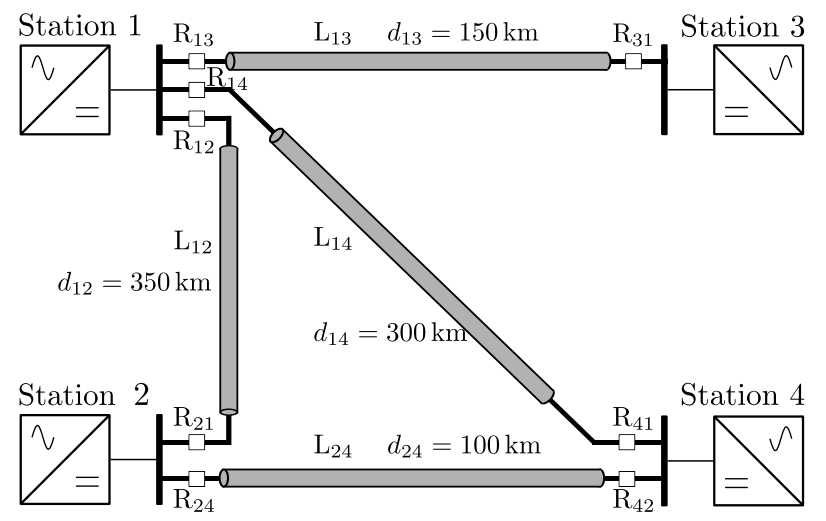

Fig. 1. Example of a four-station meshed HVDC grid: Each transmission line is protected by the 2 relays located at both ends of the line.

\section{PROPOSED APPROACH}

In this section, an overview of the proposed fault identification approach is presented.
An MTDC grid is described by a graph $\mathcal{G}=(\mathcal{V}, \mathcal{E})$, where $\mathcal{E}$ is a set of edges, representing the lines connecting pairs of substations which form the vertices in $\mathcal{V}$. Within the substation represented by $q \in \mathcal{V}$, each line connected to $q$ is assumed to be monitored by a relay in charge of determining whether the line under protection is faulty as well as the type of fault (e.g., pole-to-pole, pole-to-ground).

Consider a fault occurring at some time instant $t_{\mathrm{f}}$ on a given line $e=\left(q, q^{\prime}\right) \in \mathcal{E}$ of length $d_{q q^{\prime}}$ connecting the substations $q$ and $q^{\prime}$. The transmission line $e$ is composed of $n_{\mathrm{c}}$ pole conductors. The distances between the fault and the stations $q$ and $q^{\prime}$ are $d_{\mathrm{f}, q}$ and $d_{\mathrm{f}, q^{\prime}}=d_{q q^{\prime}}-d_{\mathrm{f}, q}$. The fault is assumed to be characterized by its pole-to-ground or pole-topole impedance $Z_{\mathrm{f}}$ depending on the type of fault, considered constant during the time interval of interest in the order of a millisecond [11]. A fault can hence be described by the vector of the fault parameters $\mathbf{p}=\left(e, d_{\mathrm{f}, q}, Z_{\mathrm{f}}, t_{\mathrm{f}}\right)^{\mathrm{T}}$. Each relay is able to determine whether the grid behaves normally by comparing the peak value of the measured voltage derivative to a pre-determined threshold, see for instance [12]. When a fault is suspected, each relay must then confirm or deny that a fault occurred on their protected line. Thus, the line $e$ in $\mathbf{p}$ is fixed during the fault identification process. Furthermore $d_{\mathrm{f}, q}$ and $t_{\mathrm{f}}$ are linked through the detection time of the first TW at relay located at node $q$,

$$
t_{\mathrm{d}, q}=t_{\mathrm{f}}+\frac{d_{\mathrm{f}, q}}{c_{\mathrm{a}}},
$$

which can be measured. In (1), $c_{\mathrm{a}}$ is the propagation speed of the TW, see Section III-A. Thus the vector of the fault parameters can be reduced to $\mathbf{p}=\left(d_{\mathrm{f}, q}, Z_{\mathrm{f}}\right)^{\mathrm{T}}$.

The relay at substation $q$ monitoring line $e$ acquires voltage and current measurements $\left(\mathbf{v}_{q, e}(t), \mathbf{i}_{q, e}(t)\right)$ from the sensors located at the end of $e$, where the voltage and current vectors $\mathbf{v}_{q, e}=\left(v_{q, e}^{1}, \ldots, v_{q, e}^{n_{\mathrm{c}}}\right)^{T}$ and $\mathbf{i}_{q, e}=\left(i_{q, e}^{1}, \ldots, i_{q, e}^{n_{\mathrm{c}}}\right)^{T}$ gather the data for all the $n_{\mathrm{c}}$ conductors. One has first to determine whether the grid behaves normally or not and the suspected type of fault (pole-to-pole, pole-to-ground), using, e.g., [13].

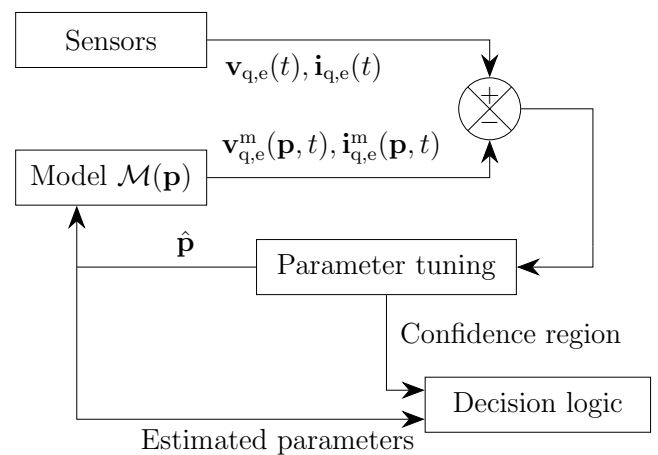

Fig. 2. Overview of the proposed fault identification approach.

To identify the fault, the proposed approach, sketched in Figure (2), considers a parametric model $\mathcal{M}(\mathbf{p})$ of the evolution of voltage and current at node $q$ when a fault occurs. The output at time $t$ of the model for all the pole conductors is denoted $\left(\mathbf{v}_{q, e}^{\mathrm{m}}(\mathbf{p}, t), \mathbf{i}_{q, e}^{\mathrm{m}}(\mathbf{p}, t)\right)$. The model depends on the 
known characteristics of the grid and on the value of the vector $\mathbf{p}$ of the fault parameters. A Maximum Likelihood (ML) estimate of $\mathbf{p}$ is evaluated from the voltage and current measurements $\left(\mathbf{v}_{q, e}(t), \mathbf{i}_{q, e}(t)\right)$. In what follows, since the considered relay at substation $q$ monitoring line $e$ is fixed and the subscripts $q$ and $e$ are omitted to lighten the notations.

Consider that the fault actually occurred on the line $e$ with parameters $\mathbf{p}^{*}$. Assuming that the voltage and current measurements noise samples are zero-mean Gaussian and uncorrelated, the ML estimate $\widehat{\mathbf{p}}$ of $\mathbf{p}^{*}$ leads to the minimization of the following cost function [14]

$$
c^{(n)}(\mathbf{p})=\mathbf{f}^{(n)}(\mathbf{p})^{T}\left[\Sigma^{(n)}\right]^{-1} \mathbf{f}^{(n)}(\mathbf{p}),
$$

where $\mathbf{f}^{(n)}(\mathbf{p})$ is the vector of the residuals of the $n$ observations,

$$
\begin{gathered}
\mathbf{f}^{(n)}(\mathbf{p})=\left[\left(\mathbf{v}\left(t_{1}\right)-\mathbf{v}^{\mathrm{m}}\left(\mathbf{p}, t_{1}\right)\right)^{T}, \ldots,\left(\mathbf{v}\left(t_{n}\right)-\mathbf{v}^{\mathrm{m}}\left(\mathbf{p}, t_{n}\right)\right)^{T}\right. \\
\left.\left(\mathbf{i}\left(t_{1}\right)-\mathbf{i}^{\mathrm{m}}\left(\mathbf{p}, t_{1}\right)\right)^{T}, \ldots,\left(\mathbf{i}\left(t_{n}\right)-\mathbf{i}^{\mathrm{m}}\left(\mathbf{p}, t_{n}\right)\right)^{T}\right]^{T} \cdot
\end{gathered}
$$

$\left[\Sigma^{(n)}\right]$ is a matrix containing the measurement noise variances depending on the voltage and current sensors. Starting from an initial point $\mathbf{p}_{\text {init }}$, the optimization algorithm performs $\kappa$ iterations using the Levenberg-Marquardt algorithm [14].

From the parameter estimation results, the identification algorithm has to confirm or deny the initial hypothesis that the fault occurred on the protected line $e$. For each $\widehat{\mathbf{p}}$, an approximate confidence region $\mathcal{R}^{(\alpha)}(\widehat{\mathbf{p}})$ is evaluated. To determine whether the estimate is consistent with the hypothesis that the monitored line is faulty, two tests are considered. First, a validity test determines whether $\widehat{\mathbf{p}}$ is included in some domain of interest, i.e., if

$$
d_{\min } \leq \widehat{d}_{\mathrm{f}} \leq d_{\max } \text { and } R_{\min } \leq \widehat{R}_{\mathrm{f}} \leq R_{\max }
$$

where the boundaries represent plausible values for the fault distance and resistance, which should for instance be positive. Second, an accuracy test determines whether the area of the $95 \%$ confidence region $\mathcal{R}^{(\alpha)}(\widehat{\mathbf{p}})$ goes under some threshold $c_{95}$. This confidence region is computed based on the Fisher information matrix [14]. If both tests are satisfied, the fault is identified on line $e$. When it is unable to conclude, the algorithm waits for the availability of $\Delta n$ additional measurements to perform $\kappa$ new iterations and update $\widehat{\mathbf{p}}$ and $\mathcal{R}^{(\alpha)}(\widehat{\mathbf{p}})$. Thus the estimation algorithm uses all the available measurements at each time by increasing regularly the size of the residuals (3). Once enough measurements have been made available without allowing the algorithm to conclude that the fault is on the line $e$, the fault is deemed to be located elsewhere in the grid, or to be non-existent. More details on the parameter estimation process can be found in [9].

\section{DC FAULT MODELING IN MULTI-CONDUCTOR TRANSMISSION LINES}

This section develops a time-domain model of the transient evolution of the voltage and current valid on a short time interval following the fault occurrence. It involves a description of the traveling waves generated by the fault and a modal analysis presented in Section III-A. Section III-B introduces a behavioral approach to take into account the distortion due to the ground effects. This combined approach allows one to obtain a parametric model of any TW through the grid, see Section III-C.

\section{A. Traveling waves and modal analysis}

A fault occurring on a transmission line induces a transient behavior that can be described by traveling waves. A detailed presentation of the theory of propagation on multi-conductor OHL can be found in [15]. The main results are briefly reminded here to introduce the useful notations.

The evolution of the voltage and current on a transmission line with $n_{\mathrm{c}}$ pole conductors is described by the Telegrapher's equations in the Laplace domain

$$
\begin{aligned}
\frac{\partial^{2} \mathbf{V}(x, s)}{\partial x^{2}} & =[Z(s)][Y(s)] \mathbf{V}(x, s) \\
\frac{\partial^{2} \mathbf{I}(x, s)}{\partial x^{2}} & =[Y(s)][Z(s)] \mathbf{I}(x, s)
\end{aligned}
$$

where $\mathbf{V}$ and $\mathbf{I}$ are $n_{\mathrm{c}}$-dimensional vectors gathering the phase voltages and currents, respectively. $[Z(s)]=[R]+s[L]$ and $[Y(s)]=[G]+s[C]$ are the distributed series impedance and shunt admittance matrices, respectively. In this section the distributed parameter matrices $[R],[L],[G]$, and $[C]$ are considered at a fixed frequency. Since the influence of conductor $i$ on conductor $j$ is identical to the influence of conductor $j$ on $i$, the matrices $[Z(s)]$ and $[Y(s)]$ are symmetric. Thus there exists a unitary matrix (in practice real) $\left[T_{\mathrm{V}}\right]$ such that

$$
[Z(s)][Y(s)]=\left[T_{\mathrm{V}}\right]^{T}\left[D_{Z Y}(s)\right]\left[T_{\mathrm{V}}\right]
$$

where $\left[D_{Z Y}(s)\right]$ is a diagonal matrix gathering the eigenvalues of $[Z(s)][Y(s)]$. The modal (or component) voltages and currents are defined as

$$
\begin{aligned}
\mathbf{V}^{\mathrm{c}} & =\left[T_{\mathrm{V}}\right] \mathbf{V} \\
\mathbf{I}^{\mathrm{c}} & =\left[T_{\mathrm{V}}\right]^{T} \mathbf{I}
\end{aligned}
$$

The solution of (5) consists of the superposition of two waves traveling in opposite directions. The wave traveling towards the positive $x$ is

$$
\mathbf{V}^{\mathrm{c}}(x, s)=\underbrace{\exp (-[\Gamma(s)] x)}_{=[H(x, s)]} \mathbf{V}_{\text {init }}^{\mathrm{c}}(s)
$$

where $\mathbf{V}_{\text {init }}^{\mathrm{c}}$ is the initial surge at the fault location computed in modal domain and $[\Gamma(s)]=\sqrt{\left[D_{Z Y}(s)\right]}$ is the propagation matrix. The elements of $[\Gamma]$ can be divided into real and imaginary parts which account respectively for the attenuation and the propagation of the different modes along the line. The slowest mode, or ground mode, is placed in the first position in $\mathbf{V}^{\mathrm{c}}$ while the aerial modes, which travel faster, occupy the remaining positions. The phase current waves are related to the phase voltage waves through the surge (or characteristic) admittance matrix $\left[Y_{\mathrm{s}}\right]$

$$
\mathbf{I}(x, s)=\left[Y_{\mathrm{s}}(s)\right] \mathbf{V}(x, s)
$$

where

$$
\left[Y_{\mathrm{s}}(s)\right]=[Z(s)]^{-1}\left[T_{\mathrm{V}}\right]^{T}[\Gamma(s)]\left[T_{\mathrm{V}}\right]
$$


The surge admittance matrix can also be computed in modal domain so that modal voltages and currents are related similarly as in (10).

When a change of propagation medium occurs (e.g., at the junction between a line and a station), the forward wave $\mathbf{V}_{\mathrm{f}}$ gives rise to a transmitted wave $V_{t}$ and a reflected wave $V_{r}$,

$$
\begin{aligned}
\mathbf{V}_{\mathrm{t}} & =\mathbf{V}_{\mathrm{f}}+\mathbf{V}_{\mathrm{r}} \\
& =\left(\left[I_{n_{\mathrm{c}}}\right]+[K]\right) \mathbf{V}_{\mathrm{f}} \\
& =[T] \mathbf{V}_{\mathrm{f}},
\end{aligned}
$$

where the transmission and reflection matrices $[T]$ and $[K]$ depend on the surge admittances of the media. Consider a wave from medium 1 of surge admittance $\left[Y_{\mathrm{s}, 1}\right]$ propagating towards $n-1$ media of surge admittances $\left[Y_{\mathrm{s}, 2}\right], \ldots,\left[Y_{\mathrm{s}, n}\right]$. The reflection matrix is then

$$
\left[K_{1 \rightarrow 2 \ldots n}\right]=\left(\sum_{\ell=1}^{n}\left[Y_{\mathrm{s}, \ell}\right)^{-1}\left(\left[Y_{\mathrm{s}, 1}\right]-\sum_{\ell=2}^{n}\left[Y_{\mathrm{s}, \ell}\right]\right) .\right.
$$

Any reflection (resp. transmission) matrix $[K]$ (resp. $[T]$ ) can be defined in modal domain using the transformation matrix

$$
\left[K^{\mathrm{c}}\right]=\left[T_{\mathrm{V}}\right][K]\left[T_{\mathrm{V}}\right]^{T} .
$$

For reflections occurring at the junction with a converter station, approximate models are considered, for instance RLC equivalents to compute the surge impedances of the stations, see [16].

The initial surge at the fault location is

$$
\mathbf{V}_{\text {init }}\left(R_{\mathrm{f}}, s\right)=\left[K_{\mathrm{e} \rightarrow \mathrm{f}}\right] \frac{\exp \left(-t_{\mathrm{f}} s\right)}{s} \mathbf{V}_{\mathrm{bf}} .
$$

where $\mathbf{V}_{\mathrm{bf}}$ is the vector of phase voltages at the fault location just before the fault occurrence, and $\left[K_{\mathrm{e} \rightarrow \mathrm{f}}\right]$ is the reflection matrix from line $e$ to the fault

$$
\left[K_{\mathrm{e} \rightarrow \mathrm{f}}\right]=-\left(2\left[Y_{\mathrm{s}, e}\right]+\left[Y_{\mathrm{s}, \mathrm{f}}\right]\right)^{-1}\left(\left[Y_{\mathrm{s}, \mathrm{f}}\right]\right) .
$$

The fault surge admittance matrix $\left[Y_{\mathrm{s}, \mathrm{f}}\right]$ is an $\left(n_{\mathrm{c}}, n_{\mathrm{c}}\right)$ matrix with non-zero elements in the entries corresponding to the conductor(s) affected by the fault. For a fault between the $i^{\text {th }}$ conductor and the ground with fault resistance $R_{\mathrm{f}}$, one has

$$
\left[Y_{\mathrm{s}, \mathrm{f}}\right]_{i i}=\frac{1}{R_{\mathrm{f}}}
$$

while for a fault between conductors $i$ and $j$ with fault resistance $R_{\mathrm{f}}$, one has

$$
\left[Y_{\mathrm{s}, \mathrm{f}}\right]_{i j}=\left[Y_{\mathrm{s}, \mathrm{f}}\right]_{j i}=\frac{1}{R_{\mathrm{f}}} .
$$

The initial surge in modal domain is thus

$$
\mathbf{V}_{\text {init }}^{\mathrm{c}}\left(s, R_{\mathrm{f}}\right)=\left[T_{V}\right]\left[K_{\mathrm{e} \rightarrow \mathrm{f}}\left(R_{\mathrm{f}}\right)\right] \frac{\exp \left(-t_{\mathrm{f}} s\right)}{s} \mathbf{V}_{\mathrm{bf}}
$$

which depends on the fault resistance $R_{\mathrm{f}}$.

The model of the first TW starting from the fault location that arrives and is reflected at the substation $q$ after traveling a distance $d_{\mathrm{f}}$ is thus, in modal domain,

$$
\begin{aligned}
& \mathbf{V}_{\mathrm{f}, \mathrm{c}}^{\mathrm{m}, \mathrm{c}}(\mathbf{p}, s)=\left[H\left(d_{\mathrm{f}}, s\right)\right] \mathbf{V}_{\text {init }}^{\mathrm{c}}\left(R_{\mathrm{f}}, s\right) \\
& \mathbf{V}_{\mathrm{r}, \mathrm{c}}^{\mathrm{m}, \mathrm{c}}(\mathbf{p}, s)=\left[K_{\mathrm{q}}^{\mathrm{c}}\right] \mathbf{V}_{\mathrm{f}, 1}^{\mathrm{m}, \mathrm{c}}(\mathbf{p}, s)
\end{aligned}
$$

where $\left[K_{\mathrm{q}}^{\mathrm{c}}\right]$ is the reflection matrix from line $e$ to station $q$.

The inverse Laplace transform is then applied to get the time domain expressions $\mathbf{v}_{\mathrm{f}, i}^{\mathrm{m}, \mathrm{c}}(\mathbf{p}, t)$ and $\mathbf{v}_{\mathrm{r}, i}^{\mathrm{m}, \mathrm{c}}(\mathbf{p}, t)$. Similar derivations may be performed for the current using the surge admittance (10).

\section{B. Behavioral modeling including the ground effects}

In Section III-A, the matrices $[R],[L],[G]$, and $[C]$ have been assumed independent of $s$. In practice, $[L]$ and $[R]$ are frequency-dependent. Taking this dependency into account significantly increases the complexity of the evaluation of the time-domain expressions of the TWs.

This section presents a combined physical and behavioral approach to represent the frequency-dependent effects while keeping the evaluations of the expression of the TWs at a manageable level. This approach extends the one proposed in [9], which addresses the particular case of a single-conductor transmission line.

First, one considers a lossless model, in which $[Z(s)] \simeq$ $s[L]$ and $[Y(s)] \simeq s[C]$. This is consistent with the highfrequency components of the transients, leading to negligible series resistance and shunt conductance with respect to the effects of $s[L]$ and $s[C]$.

The dependence of $[L]$ with frequency impacts unequally the different modes. While the ground mode endures significant distortion and time delay due to the impact of the soil resistivity on $[L]$, the aerial modes travel with negligible attenuation and at a speed which does not depend on the frequency, as evidenced in [17]. Thus the matrix $[H(x, s)]$ in (9) can be expressed as the product of a term $\left[H_{\mathrm{g}}(x, s)\right]$ accounting for the ground mode distortion only and a term $\left[H_{0}(x, s)\right]$ representing the propagation delays

$$
[H(x, s)]=\left[H_{\mathrm{g}}(x, s)\right]\left[H_{0}(x, s)\right] .
$$

In (15), $\left[H_{0}(x, s)\right]=\exp \left(-\left[\Gamma_{0}(s)\right] x\right)$ and the matrix $\left[\Gamma_{0}\right]$ is computed using the lossless line distributed parameters at a fixed frequency $f_{0}$, i.e.,

$$
\left[\Gamma_{0}(s)\right]=s \sqrt{\left[T_{V}\right]\left[L_{0}\right]\left[C_{0}\right]\left[T_{V}\right]^{T}} .
$$

The distortion of the ground mode is modeled using a rational transfer function of orders $n_{a}$ and $n_{b}$ with coefficients $\left(a_{1}, \ldots, a_{n_{a}}, b_{0}, \ldots, b_{n_{b}}\right)$

$$
\left[H_{\mathrm{g}}(x, s)\right]=\left(\begin{array}{cccc}
\frac{b_{0}+b_{1} s+\cdots+b_{n_{b}} s^{n_{b}}}{1+a_{1} s+\ldots a_{n_{a}} s^{n_{a}}} & 0 & \ldots & 0 \\
0 & 1 & & \\
\vdots & & \ddots & 0 \\
0 & & 0 & 1
\end{array}\right) .
$$

As the distortion due to the soil resistivity depends on the distance traveled by the wave, the coefficients of the ground filter $H_{\mathrm{g}}$ should depend on the fault distance $d_{\mathrm{f}}$. The speed of the ground mode

$$
c_{\mathrm{g}}\left(d_{\mathrm{f}}, s\right)=\left\|\left[\Gamma_{0}(s)\right]_{1,1}\right\|^{-1}
$$

is also frequency dependent and thus also varies with the traveled distance [18]. 
For a given fault distance $d_{\mathrm{f}}$, the parameters of the filter $H_{\mathrm{g}}$ and the ground speed mode $c_{\mathrm{g}}$ can be identified so that the simulated voltage for the first forward TW $\mathbf{v}_{\mathrm{f}, 1}^{\mathrm{c}}$ fits the modeled wave $\mathbf{v}_{\mathrm{f}, 1}^{\mathrm{m}, \mathrm{c}}$. The vector of parameters $\boldsymbol{\theta}=\left(a_{1}, \ldots, a_{n_{a}}, b_{0}, \ldots, b_{n_{b}}, c_{\mathrm{g}}\right)$ can be tuned, e.g., by leastsquares estimation. In practice, we propose to use a firstorder filter for the ground mode, i.e., $n_{a}=1, n_{b}=0$. Multiple fault cases are then simulated with fault distances $\left\{d_{\mathrm{f}, 1}, d_{\mathrm{f}, 2}, \ldots, d_{\mathrm{f}, \ell}\right\}$. For each fault distance $d_{\mathrm{f}, i}$, an estimate $\widehat{\boldsymbol{\theta}}_{i}$ of $\boldsymbol{\theta}$ is then obtained.

The dependence in $d_{\mathrm{f}}$ of the components of $\boldsymbol{\theta}$ is then modeled. The following polynomial model in $d_{\mathrm{f}}$ is proposed for the parameters of the ground mode filter

$$
\begin{aligned}
& b_{0}^{\mathrm{m}}\left(d_{\mathrm{f}}\right)=\beta_{0,0}+\beta_{0,1} d_{\mathrm{f}}+\beta_{0,2} d_{\mathrm{f}}^{2} \\
& a_{1}^{\mathrm{m}}\left(d_{\mathrm{f}}\right)=1+\alpha_{1} d_{\mathrm{f}} .
\end{aligned}
$$

The ground mode speed evolution with $d_{\mathrm{f}}$ is modeled as

$$
c_{\mathrm{g}}^{\mathrm{m}}\left(d_{\mathrm{f}}\right)=c_{\mathrm{a}} \exp \left(\gamma_{0}+\gamma_{1} d_{\mathrm{f}}+\gamma_{2} d_{\mathrm{f}}^{2}\right),
$$

where $c_{\mathrm{a}}$ is the speed of the aerial mode, in practice taken equal to the speed of light. The parameters $\alpha_{i}, \beta_{i}, \gamma_{i}$ are tuned by least-squares estimation from $d_{\mathrm{f}, i}$ and $\widehat{\boldsymbol{\theta}}_{i}, i=1, \ldots, \ell$.

The results of this approach on a 2 -conductor rigid bipole configuration is shown in Section IV-B.

\section{Parametric model of any $T W$}

Using the traveling waves and modal analysis developed in Section III-A along with the behavioral model proposed in Section III-B to take into account the soil resistivity effects, one can obtain explicit expressions for any TW due to the fault. These analytic expressions depend explicitly on the fault parameters $\mathbf{p}=\left(d_{\mathrm{f}}, R_{\mathrm{f}}\right)^{\mathrm{T}}$. As seen in (14), the first forward and reflected TWs reaching the station $q$ are expressed in modal domain as

$$
\begin{aligned}
& \mathbf{V}_{\mathrm{f}, 1}^{\mathrm{m}, \mathrm{c}}(\mathbf{p}, s)=\left[H_{\mathrm{g}}\left(d_{\mathrm{f}}, s\right)\right]\left[H_{0}\left(d_{\mathrm{f}}, s\right)\right] \mathbf{V}_{\text {init }}^{\mathrm{c}}\left(R_{\mathrm{f}}, s\right) \\
& \mathbf{V}_{\mathrm{r}, 1}^{\mathrm{m}, \mathrm{c}}(\mathbf{p}, s)=\left[K_{\mathrm{q}}^{\mathrm{c}}(s)\right] \mathbf{V}_{\mathrm{f}, 1}^{\mathrm{m}, \mathrm{c}}(\mathbf{p}, s) .
\end{aligned}
$$

The wave due to the reflection of $\mathbf{V}_{\mathrm{r}, 1}^{\mathrm{c}}$ at the fault location and back towards the station $q$ is

$$
\begin{aligned}
& \mathbf{V}_{\mathrm{f}, 2}^{\mathrm{m}, \mathrm{c}}(\mathbf{p}, s)=\left[H_{g}\right]\left[H_{0}\right]\left[K_{\mathrm{e} \rightarrow \mathrm{f}}^{\mathrm{c}}\right]\left[H_{g}\right]\left[H_{0}\right] \mathbf{V}_{\mathrm{r}, 1}^{\mathrm{m}, \mathrm{c}} \\
& \mathbf{V}_{\mathrm{r}, 2}^{\mathrm{m}, \mathrm{c}}(\mathbf{p}, s)=\left[K_{\mathrm{q}}^{\mathrm{c}}\right] \mathbf{V}_{\mathrm{f}, 2}^{\mathrm{m}, \mathrm{c}} .
\end{aligned}
$$

The different waves traveling through the grid can be represented using a Bewley lattice diagram, see for instance [17]. The first waves are plotted in the case of a point-to-point link between stations $q$ and $q^{\prime}$ in Figure 3. The aerial (in blue) and ground (in brown) modes travel at different speeds along the transmission line but are mixed when reaching a station. This illustrates that the different TWs consist of waves with different arrival times. In Figure 3, from (19) and (20), one has $\mathbf{V}_{1}^{\mathrm{m}, \mathrm{c}}=\mathbf{V}_{\mathrm{f}, 1}^{\mathrm{m}, \mathrm{c}}+\mathbf{V}_{\mathrm{r}, 1}^{\mathrm{m}, \mathrm{c}}$ and $\mathbf{V}_{2}^{\mathrm{m}, \mathrm{c}}=\mathbf{V}_{\mathrm{f}, 2}^{\mathrm{m}, \mathrm{c}}+\mathbf{V}_{\mathrm{r}, 2}^{\mathrm{m}, \mathrm{c}}$.

One can get back to temporal domain expressions by applying the inverse Laplace transform. Formulas for the current can be derived from the voltage using the surge admittance matrix (10). Phase quantities are obtained from the modal expressions using the inverse transformation matrices, see (7) and (8). In

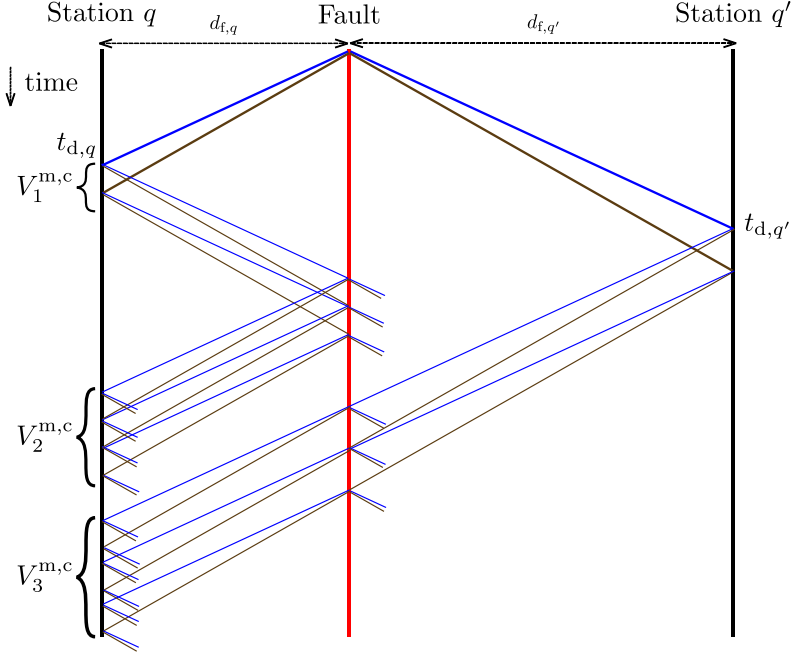

Fig. 3. Example of a Bewley lattice diagram for a point-to-point link; The aerial (blue) modes and the ground (brown) mode travel at different speeds along the transmission line.

practice, the modal quantities $\mathbf{y}^{\mathrm{m}, \mathrm{c}}$ are preferred to the phase quantities $\mathbf{y}^{\mathrm{m}}$ to perform the fault parameter estimation in Section II. This is more convenient since modal quantities have variations of similar magnitudes whereas the faulty pole has larger variations than the healthy ones.

\section{Simulation RESUlTS: MODEL EVALUATION}

This section presents the simulation results of the developed model using the test-grid detailed in Section IV-A implemented in the EMT software EMTP-RV [10]. The model developed in Section III is compared against EMT simulations in Section IV-B.

\section{A. Test grid}

The test grid implemented in EMTP-RV used for the simulation comprises 4 converter stations with half-bridge MMC as presented in Figure 1. The OHL are composed of a positive and a negative pole connected as a rigid bipole [19] with 2 ground wires for lightning strike protection. The configuration of the transmission lines obtained from [20] is listed in the Table I. The soil resistivity is considered uniform with a constant value of $\rho=100 \Omega \mathrm{m}$. In the EMT software, the transmission lines are modeled using the wideband model while the converter stations employ the model 3: switching function of arm [21]. The simulation data are assumed to be provided to the algorithm by ideal sensors with a sampling frequency $f_{\mathrm{s}}=1 \mathrm{MHz}$. The impact of a lower sampling frequency and more realistic sensors are discussed in Section V-A3. The

TABLE I

CONFIGURATION OF THE OVERHEAD TRANSMISSION LINES

\begin{tabular}{ccc}
\hline & Poles & Ground wires \\
\hline \hline DC resistance $(\Omega / \mathrm{km})$ & 0.024 & 1.62 \\
Height at tower $(\mathrm{m})$ & 37.2 & 41.7 \\
Height at mid-span $(\mathrm{m})$ & 22.2 & 26.7 \\
Horizontal distance $(\mathrm{m})$ & \pm 4.465 & \pm 3.66 \\
Outside diameter $(\mathrm{cm})$ & 4.775 & 0.98 \\
\hline
\end{tabular}


parameters of the MMC stations are listed in Table II.

TABLE II

CHARACTERISTICS OF THE MMC STATIONS

\begin{tabular}{lr}
\hline Rated power $(\mathrm{MW})$ & 1000 \\
DC rated voltage $(\mathrm{kV})$ & 320 \\
Arm inductance (p.u.) & 0.15 \\
Capacitor energy in each submodule $(\mathrm{kJ} / \mathrm{MVA})$ & 40 \\
Conduction losses of each IGBT/diode $(\Omega)$ & 0.001 \\
Number of sub-modules per arm & 400 \\
Grounding impedance $(\Omega)$ & 0.5 \\
\hline
\end{tabular}

\section{B. Ground effects modeling results}

This section presents the results of the behavioral modeling approach proposed in Section III-B in for the OHL described in Table I. Several pole-to-ground faults are simulated in EMTP-RV with $n_{\mathrm{d}}$ fault distances ranging from 10 to 400 $\mathrm{km}$. For each fault, the simulated first incident wave is used to perform a least-squares estimation of the parameters of the ground filter as well as the speed of the ground mode as a function of $d_{\mathrm{f}}$, according to (16), (17), and (18). Those models present a good fit with the identified parameters as can be seen in Figures 4 and 5.
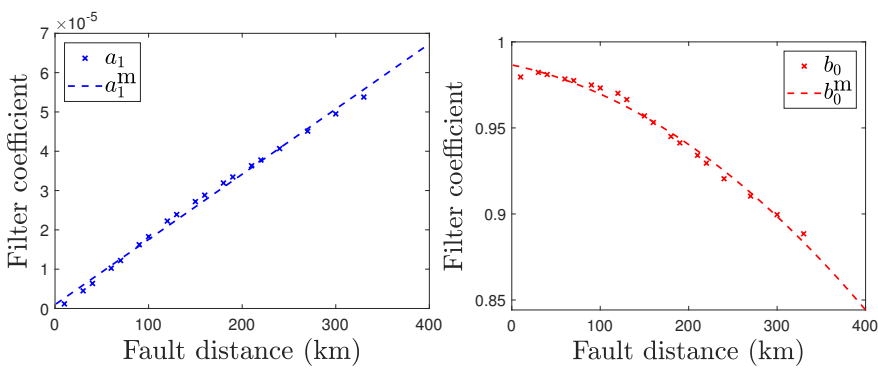

Fig. 4. Evolution of the estimated ground filter coefficients $b_{0}\left(d_{\mathrm{f}, i}\right)$ and $a_{1}\left(d_{\mathrm{f}, i}\right), i=1, \ldots, n_{\mathrm{d}}$ and of their models $b_{0}^{\mathrm{m}}\left(d_{\mathrm{f}}\right)$ and $a_{1}^{\mathrm{m}}\left(d_{\mathrm{f}}\right)$ as a function of the fault distance $d_{\mathrm{f}}$

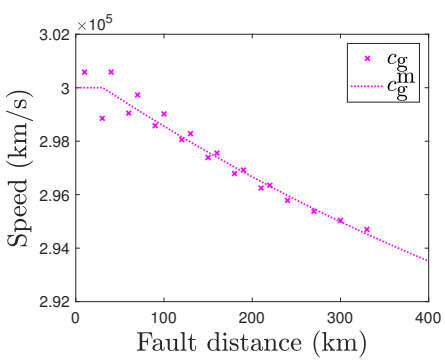

Fig. 5. Evolution of the estimates of the ground mode speed $c_{\mathrm{g}}\left(d_{\mathrm{f}, i}\right), i=$ $1, \ldots, n_{\mathrm{d}}$ and of its model $c_{\mathrm{g}}^{\mathrm{m}}\left(d_{\mathrm{f}}\right)$ as a function of the fault distance

The model introduced in Section III to describe the transient evolution of the voltage and current after a fault is compared with EMT data on a particular example. For that purpose, the models of the ground filter coefficients $b_{0}^{\mathrm{m}}\left(d_{\mathrm{f}}\right)$ and $a_{1}^{\mathrm{m}}\left(d_{\mathrm{f}}\right)$ and of the ground mode speed $c_{\mathrm{g}}^{\mathrm{m}}\left(d_{\mathrm{f}}\right)$ are employed.

Consider a positive pole-to-ground fault occurring on line $L_{14}$ of the network represented in Figure 1, located at $d_{\mathrm{f}}=$ $60 \mathrm{~km}$ from the station 1 with an impedance $R_{\mathrm{f}}=10 \Omega$. The model of the two first TWs described by (19) and (20) is compared in Figure 6 with the TWs obtained from a plain EMT simulation. In Figure 6, the voltages are on the left and the currents are on the right sub-figures, while the positive and negative poles are respectively plotted on the top and bottom sub-figures. The error between the model of the two first TWs and the EMT simulation during the first $0.8 \mathrm{~ms}$ is less than $10 \mathrm{kV}$ and $20 \mathrm{~A}$, which represents respectively $3.1 \%$ and $6.7 \%$ of the base values. .
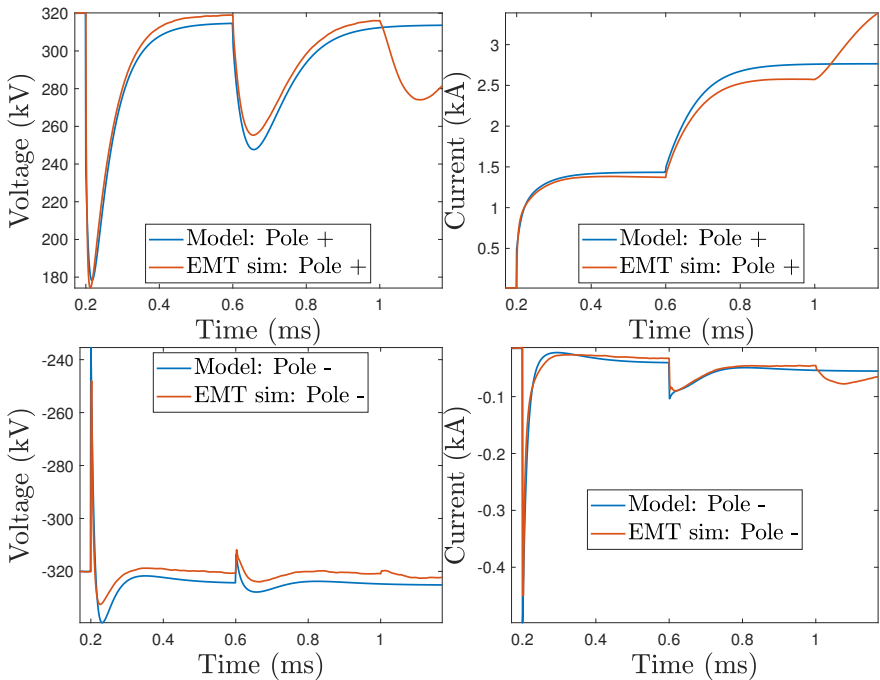

Fig. 6. Modeled and simulated phase voltage (left) and current (right) for positive (top) and negative (bottom) poles; The pole-to-ground fault is located at $d_{\mathrm{f}}=60 \mathrm{~km}$ from the station with an impedance of $R_{\mathrm{f}}=10 \Omega$ are displayed.

\section{SimUlation RESULtS: FAULT IDENTIFICATION ALGORITHM}

This section presents the simulation results for the proposed fault identification algorithm. The behavior of the algorithm is first detailed on particular fault examples in Section V-A. More extensive simulations and a comparison against a stateof-the-art method are provided in Section V-B.

\section{A. Detailed analysis on particular examples}

The behavior of the fault identification algorithm in case of internal and external faults is described in Sections V-A1 and $\mathrm{V}-\mathrm{A} 2$, respectively. The influence of the sampling frequency on the algorithm performances is investigated in Section V-A3.

1) Internal faults: dependability of the algorithm: The main tuning parameters of the identification algorithm introduced in Section II are summarized in Table III. Consider a positive

TABLE III

MAIN PARAMETERS OF THE FAULT IDENTIFICATION ALGORITHM

\begin{tabular}{cc}
\hline Number of iterations $\kappa$ & 1 \\
\hline Additional data points $\Delta n$ & 10 \\
\hline Initial point $\mathbf{p}_{\text {init }}$ & $(5 \Omega, 5 \mathrm{~km})$ \\
\hline$d_{\min }, d_{\max }$ & $(0,0.9 d)$ \\
\hline$R_{\min }, R_{\max }$ & $(0 \Omega, 250 \Omega)$ \\
\hline $95 \%$ area threshold $c_{95}$ & 20 \\
\hline
\end{tabular}


pole-to-ground fault occurring on line $L_{14}$ within the 4 stations grid of Figure 1. The fault is located at $d_{\mathrm{f}}^{*}=180 \mathrm{~km}$ from station 1 and has an impedance $R_{\mathrm{f}}^{*}=40 \Omega$. The behavior of the algorithm at relay $R_{14}$ is first detailed, the results of the fault identification algorithm triggered at all the relays of the grid is then presented. After the fault is suspected at relay $R_{14}$ the fault parameters are estimated using the first available measurements from the voltage and current sensors. The estimation algorithm stops and identifies the fault as internal after having performed 7 iterations, corresponding to an observation window of $77 \mu \mathrm{s}$. The evolution of the estimated parameters as well as the contour of the cost function (3) are displayed in Figure 7 at iterations 4 and 7 . The estimated fault parameters after the $7^{\text {th }}$ iteration are $\widehat{R}_{\mathrm{f}}=49 \Omega$ and $\widehat{d}_{\mathrm{f}}=167 \mathrm{~km}$. While the estimated parameters get closer to the minimum of the cost function, the confidence ellipse becomes smaller and eventually small enough for the algorithm to conclude that the fault is located on the protected line.
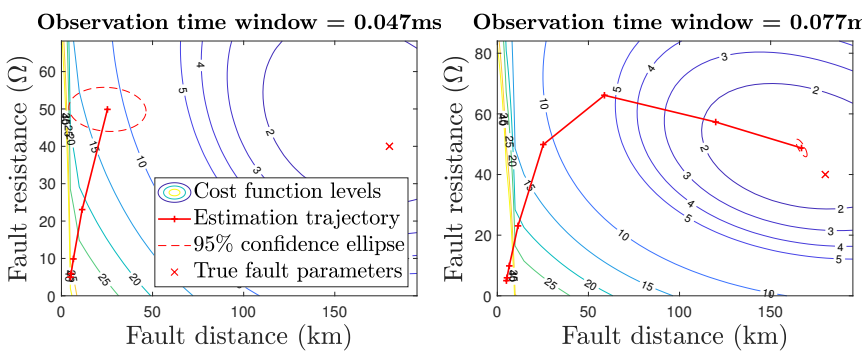

Fig. 7. Evolution of the estimated fault parameters and levels of the cost function at iterations 4 and 12. The pole-to-ground fault is located at $d_{\mathrm{f}}^{*}=$ $180 \mathrm{~km}$ from the station with an impedance of $R_{\mathrm{f}}^{*}=40 \Omega$. The estimated fault parameters after 7 iterations are $\widehat{R}_{\mathrm{f}}=49 \Omega$ and $\widehat{d}_{\mathrm{f}}=167 \mathrm{~km}$.

The EMT simulated voltages and currents are compared in the modal domain with the parametric model using the estimated fault parameters, see Figure 8. The difference in the arrival times of the ground and aerial modes, which depends on the traveled distance, improves the estimation of the fault distance. In the general case it is not possible to observe separately the ground and aerial modes at the station since they are combined through the reflection matrix (13). In this case however, the particular configuration of the 2-conductor rigid bipole implies the station does not interfere with the propagation modes for the first TW. Thus one can clearly see the ground and aerial modes in Figure 8.
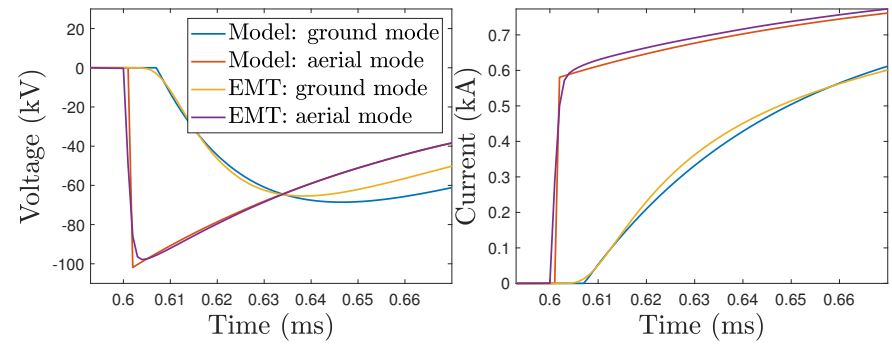

Fig. 8. Comparison of the modeled and simulated modal voltage (left) and current (right) at the relay $R_{14}$. The fault parameters used in the parametric model are those obtain after 7 iterations: $\widehat{R}_{\mathrm{f}}=49 \Omega$ and $\widehat{d}_{\mathrm{f}}=167 \mathrm{~km}$.
2) External faults: security of the algorithm: For the same fault as in V-A1, the execution of the fault identification at the eight relays of the grid is now studied. The two relays that monitor the faulty line, $R_{14}$ and $R_{41}$, should identify the fault as internal whereas the remaining six relays should identify the fault as external. The area of the confidence region of the estimated fault parameters at all the relays is displayed in Figure 9 for the maximum allowed window length, though the algorithm may stop at a relay when the fault is identified as internal. As the fault is close to the station 4 it is first detected by the relays $R_{42}$ and $R_{41}$. The latter correctly identifies the fault after a few iterations when the confidence region area goes below the threshold. At $R_{42}$ the confidence region area remains far above the threshold. A similar behavior can be observed at the station 1 where the relay $R_{14}$ identifies the fault, as detailed in Section V-A1 and the relays $R_{12}$ and $R_{13}$ conclude the fault is external. At the relay $R_{31}$ the accuracy criteria is satisfied, however the fault is not identified as internal: the estimate of the fault parameters do not satisfy the validity test, in particular $\widehat{R}_{\mathrm{f}}>R_{\max }$, see Figure 9 (right). The accuracy and validity tests are thus both required to ensure the security of the algorithm.
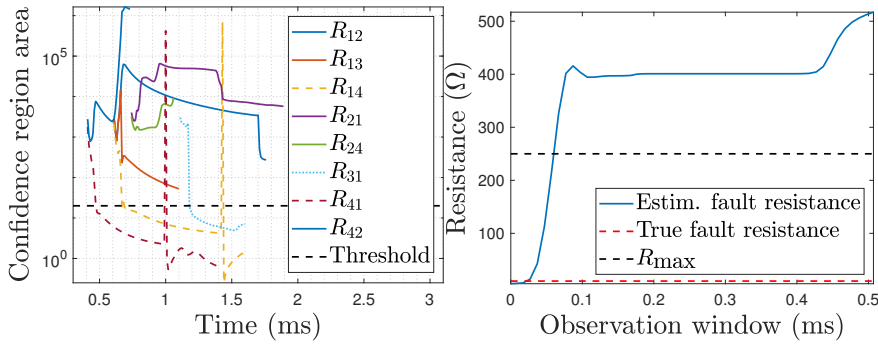

Fig. 9. Left: Evolution of the $95 \%$ confidence region area of the estimated fault parameters at the eight relays of the grid. Right: Evolution of the estimated fault resistance at the relay $R_{31}$.

3) Impact of the sampling frequency: The proposed approach has been tested with ideal EMT data considering a rather high sampling frequency $f_{\mathrm{s}}=1 \mathrm{MHz}$. The impact of more realistic measurements is studied in this section on a particular fault example. Sensor models were implemented in EMT software to account for measurements with limited bandwidth and accuracy as well as for different sampling frequencies. The main parameters of the sensors are summarized in Table IV. The maximum difference between the measured value and the true value, with respect to the base quantities for the voltage and current, or accuracy class, is set to $1 \%$. Different sampling times were simulated and the bandwidth was adjusted accordingly to fulfill Shannon's theorem. Though different sampling times for the sensors were tested, the sampling frequency for EMT simulation is maintained at $1 \mathrm{MHz}$. Consider a fault occurring on the line $L_{14}$ within the

TABLE IV

MAIN PARAMETERS EMPLOYED FOR THE SENSORS

\begin{tabular}{cccccc}
\hline Sampling frequency $(\mathrm{kHz})$ & 1000 & 500 & 250 & 166 & 100 \\
\hline Bandwidth $(\mathrm{kHz})$ & 300 & 150 & 75 & 50 & 30 \\
\hline
\end{tabular}

grid depicted in Figure 1 at a distance $d_{\mathrm{f}}=0.7 d_{14}=210 \mathrm{~km}$ 
from station 1 and $d_{\mathrm{f}}=0.3 d_{14}=90 \mathrm{~km}$ of station 4 with an impedance $R_{\mathrm{f}}=60 \Omega$. The behavior of the algorithm at the relays $R_{14}$ and $R_{41}$ are both studied. The tuning of the algorithm has been adapted so that it can cope with a reduced sampling frequency. Specifically,

- In the accuracy test, the size of the confidence region is inversely proportional to the number of sampling points. A lower sampling frequency thus results in larger confidence areas. The threshold is adjusted to the sampling frequency.

- The number of iterations the optimization algorithm for a given observation window length is kept constant. This leads to adjust $\kappa$ so that one iteration is performed every $10 \mu \mathrm{s}$.

The different settings are summarized in Table V. The identification algorithm is able to identify the two considered fault cases for frequencies such that $f_{\mathrm{s}} \geq \frac{1}{6 \times 10^{-6}}=167 \mathrm{kHz}$. For $f_{\mathrm{s}}=100 \mathrm{kHz}$ however, the algorithm fails to identify the remote fault case and has a very poor accuracy for the close fault. Furthermore, the performances of the algorithm are degraded when the sampling frequency is reduced. The required observation window may be twice as long in the worst case and the precision of the estimated parameters also decreases, see Figure 10.

TABLE V

TUNING PARAMETERS OF THE IDENTIFICATION ALGORITHM ADAPTED TO COPE WITH SLOWER SAMPLING FREQUENCIES.

\begin{tabular}{cccccc}
\hline Sampling period $(\mu \mathrm{s})$ & 1 & 2 & 4 & 6 & 10 \\
\hline Threshold $c_{95}$ & 20 & 40 & 60 & 50 & 30 \\
\hline Number of iterations $\kappa$ & 1 & 2 & 4 & 6 & 10
\end{tabular}
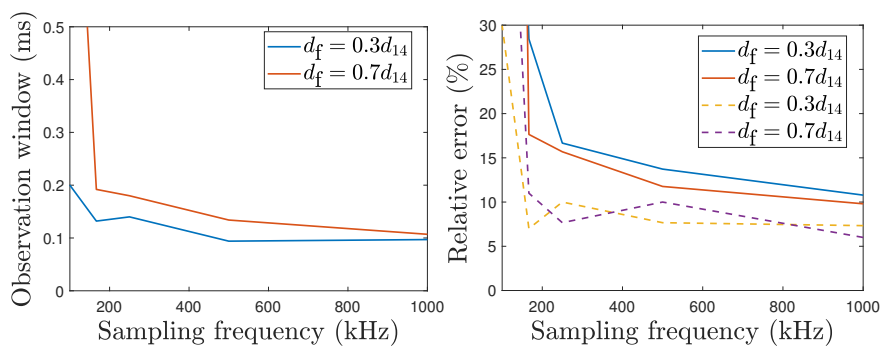

Fig. 10. Impact of the sampling frequency on the performances of the algorithm: length of the required measurement window (left) and relative error (right) of the estimated fault distance (dashed) and resistance (plain). For $f_{\mathrm{s}}=100 \mathrm{kHz}$ the algorithm fails to identify the remote fault and present a very poor accuracy for the close fault.

These preliminary results suggest the algorithm can be adapted to sampling frequencies as low as $166 \mathrm{kHz}$, at the cost of degraded performances. Nevertheless, more extensive studies would be required to confirm those results on a broader range of fault cases. In particular, the impact of using a higher threshold on the security of the algorithm should be investigated.

\section{B. Extensive simulations}

The performances of the algorithm are validated and compared with a state-of-the art method in Section V-B1. The computing times of the identification algorithm are presented in Section V-B2.

1) Fault identification performances and comparison with a reference method: To evaluate the proposed approach on a wider range of fault cases, we performed extensive simulations on the 4-station grid presented in Figure 1. Multiple positive pole-to-ground faults were simulated on different line $e$ with varying fault distance $d_{\mathrm{f}}$ and fault resistance $R_{\mathrm{f}}$, such that $e \in\left(L_{12}, L_{13}, L_{14}, L_{24}\right), R_{\mathrm{f}} \in(0,10,40,80,120,160) \Omega$ and $d_{\mathrm{f}} \in(0.01,0.1,0.2,0.4,0.6,0.8,0.9,0.99) \times d_{e}$. For each of them an abnormal behavior is detected at all the 8 relays and the fault identification is started. A total of 192 fault cases were thus simulated, leading to 1536 executions of the identification algorithm.

We compare the proposed approach with a reference fault identification algorithm presented in [22]. In this method the authors propose a behavioral model of the ground mode first current TW

$$
i_{\text {ground }}(t)=-a \exp (-b t)+c
$$

where the parameters $a, b$ and $c$ are estimated when a fault is suspected at the relay. The fault is identified on the protected line if the estimated parameter $\widehat{b}$ goes above some threshold, i.e.,

$$
\widehat{b}>b_{\mathrm{th}} .
$$

The parameters of the reference method are adjusted to the 4station grid used for the extensive simulations. The maximum value of the estimated $b$ parameters for internal fault $b_{\mathrm{se}}$ is computed using the approximated speed of the ground mode $c_{\mathrm{g}}$ and the total length of the protected line $d_{e}$

$$
b_{\mathrm{se}}=\frac{c_{\mathrm{g}}}{d_{e}} .
$$

The threshold on the parameter $b$ is then defined as $b_{\mathrm{th}}=$ $k_{\text {rel }} b_{\text {se }}$, where $k_{\text {rel }}$ is a reliability factor set to $k_{\text {rel }}=5$.

To analyze and compare the results of the two approaches, we define the dependability rate for line $e$ as the proportion of faults that are correctly identified on the faulty line,

$$
r_{\mathrm{d}}(e)=\frac{\# \text { Faults correctly identified on line } e}{\# \text { Faults that occured on line } e} .
$$

The security rate for line $e$ is the proportion of faults that where correctly identified to be outside line $e^{1}$,

$$
r_{\mathrm{s}}(e)=1-\frac{\# \text { Faults wrongly identified on line } e}{\# \text { Faults that occured outside line } e} .
$$

These indicators are given for the proposed approach and for [22] in Table VI for faults affecting the different lines. The proposed approach shows a slightly better dependability, except for the shortest line $L_{24}(100 \mathrm{~km}$ long). Furthermore, the proposed method proves to be more secure against external faults, which may be related to the difficulty to extend [22] to a grid without large DC reactors placed at the end of the lines.

The evolution of the dependability rate with the fault distance and resistance is detailed in Figure 11, showing the fault resistance only has a limited impact on the dependability.

\footnotetext{
${ }^{1}$ The proposed metrics are also known as sensitivity and specificity [23].
} 
TABLE VI

FAULT IDENTIFICATION RESULTS OF THE PROPOSED APPROACH

\begin{tabular}{cccccc}
\hline Indicator & Approach & $L_{12}$ & $L_{13}$ & $L_{14}$ & $L_{24}$ \\
\hline \hline Dependability & Proposed & $\mathbf{9 2 \%}$ & $\mathbf{9 1 \%}$ & $\mathbf{9 2 \%}$ & $91 \%$ \\
& From [22] & $90 \%$ & $88 \%$ & $82 \%$ & $\mathbf{9 5 \%}$ \\
\hline Security & Proposed & $\mathbf{9 9 \%}$ & $\mathbf{9 9 \%}$ & $\mathbf{9 9 \%}$ & $\mathbf{9 9 \%}$ \\
& From [22] & $85 \%$ & $99 \%$ & $85 \%$ & $93 \%$ \\
\hline
\end{tabular}

The influence of the fault distance resembles the feature of a distance protection: dependability failures only occur for faults located near the remote end of the protected line, in this case $d_{\mathrm{f}}^{*} \geq 0.9 d_{e}$. The length of the observation window

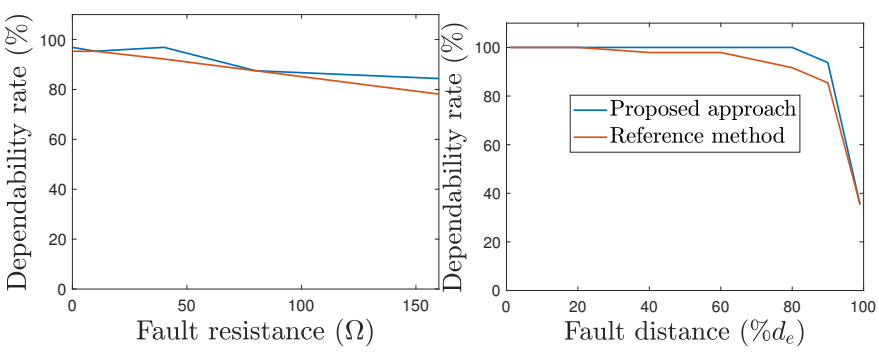

Fig. 11. Average dependability rate with the fault resistance and distance (with respect to the considered relay).

used for the identification of internal faults is displayed for all the fault cases in Figure 12 (left). The measurement window is less than $200 \mu$ s long in $93 \%$ of the fault cases for the proposed approach and only in $46 \%$ of the fault cases for the reference method. Specifically for the proposed approach, all faults occurring within the monitored portion of the line $e$, i.e., $d_{\mathrm{f}}^{*} \leq d_{\max }=0.9 d_{e}$ are identified using a window of less than $0.25 \mathrm{~ms}$. The proposed approach, indeed, stops as soon as the fault is identified whereas in [22] the algorithm waits for the arrival time of the second TW or, if possible, for the availability of $1 \mathrm{~ms}$ long data window.
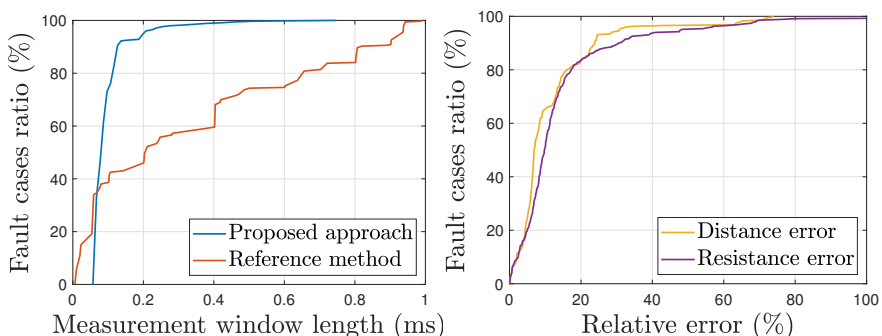

Fig. 12. Left:length of the observation window required for the identification of internal faults for the proposed approach and for the reference approach from [22]. Right: relative errors in the estimated fault distance and resistance using the proposed approach.

In addition to the reliable identification of internal faults, the approach proposed in this paper produces an estimation of the fault parameters. For internal faults that are correctly identified, the precision of the estimated fault parameters is compared to the true value of the fault parameters, see Figure 12 (right). The error rate for the fault distance is given as a percentage of the total line length, $\frac{\widehat{d}_{f}-d_{f}^{*}}{d_{e}}$ and the error rate for the fault resistance is given as a percentage of the base
DC impedance, i.e., $\frac{\widehat{R_{\mathrm{f}}}-R_{\mathrm{f}}^{*}}{Z_{\text {base }}}=\frac{\widehat{R_{\mathrm{f}}}-R_{\mathrm{f}}^{*}}{102}$. For $66 \%$ of the faults identified as internal, the relative error is less than $13 \%$ for both the fault distance and resistance. This is acceptable as the primary purpose of the algorithm is to reliable identify as fast as possible the fault on the protected line. The algorithm thus stops before it has converged to the minimum of the cost function, see Figure 7. This allows to identify the fault while using very few measurements but limits the precision of the estimated parameters.

The estimated fault parameters can be used to assess the severity of the fault. For the least severe faults, e.g., remote or high-impedance faults, an ultra-fast decision to trip the breakers may not be required. In such cases, the available time allows to wait for additional information from remote relays, making the fault identification results more reliable. The estimate of the fault parameters thus enables to adapt the fault clearing strategy to the severity of the fault.

2) Computing time: The complexity and computing time of the fault identification algorithm as implemented in Matlab is detailed in this section. The algorithm should be able to perform $\kappa$ iterations in $\frac{\Delta n}{f_{\mathrm{s}}}$ seconds. As the time constraints are mostly stringent for internal faults, we only consider here the computing times required to identify internal faults. Considering the extensive simulations performed in Section V-B, the cumulative distribution of the computing times are plotted for the identified fault cases in Figure 13 (right). For 70\% of the faults identified as internal, the computing time is less than $50 \mathrm{~ms}$, which is about 100 times more than the real time objective of $0.5 \mathrm{~ms}$ for the fault identification.

Most of the computing time of the algorithm is in the evaluation of the cost function (2) and its partial derivatives with respect to the fault parameters. This amounts to the evaluation of the different voltage waves and their derivatives. These computations are investigated apart from the rest of the algorithm using measurement widows of lengths $0.5 \mathrm{~ms}$ and $1 \mathrm{~ms}$ long and random fault parameters. The obtained execution times for one evaluation of the cost function and its partial derivatives are plotted in Figure 13 (left). The first bars correspond to faults for which the evaluation of only one wave is required, which are faults occurring relatively far from the extremities of the line. The bars further right correspond to faults that require the evaluation of two or three waves. Longer observation windows are more likely to require the computation of two or three waves, which explains that more fault cases are located to the right for the longest observation window. The length itself of the window explains the shift of the different bars to the right but has a less significant impact than the number of waves that must be computed. The performance of the developed model to compute the evolution of the voltage in the first millisecond after the fault can be compared with existing tools, in particular with EMT software. A plain EMT computation requires the simulation of the grid on hundreds of milliseconds before the fault. To compare only the evaluation of the voltage in the first millisecond after the fault, a reduced EMT model is implemented. As a comparison point, the results from [24] reduced to a observation window of $1 \mathrm{~ms}$, are also indicated. In [24], a sensitivity-based approach allows one to compute the traveling waves for any fault 


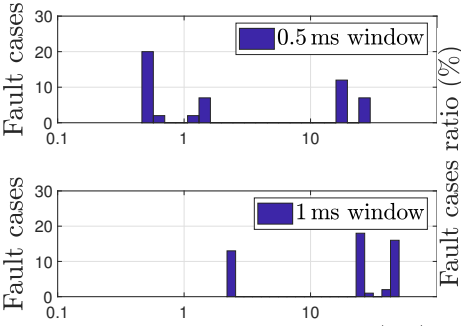

Cost function evaluation $(\mathrm{ms})$

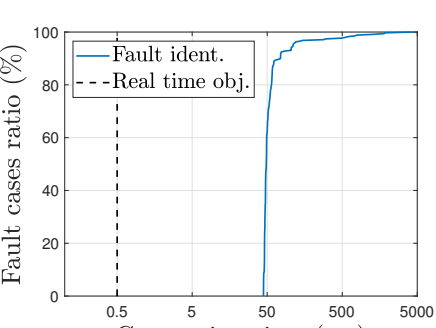

Computing time $(\mathrm{ms})$
Fig. 13. Left: Execution times required to evaluate once the cost function and its derivatives on an observation widow $0.5 \mathrm{~ms}$ (top) and $1 \mathrm{~ms}$ (bottom) long. Right: Computing times for proposed approach obtained with the extensive simulations.

resistance, assuming the remaining fault conditions are known. The results show the proposed parametric model performs well compared to existing methods, at the cost of a reduced accuracy. The performances achievable with an optimized $\mathrm{C}++$

TABLE VII

COMPARISON OF THE COMPUTATION TIMES TO EVALUATE THE VOLTAGE AND CURRENT EVOLUTION ON AN OBSERVATION WINDOW OF 1 MS.

\begin{tabular}{cc}
\hline Model & Computing times (ms) \\
\hline \hline Approach from [24] & $6-12$ \\
\hline Simplified EMT & 150 \\
\hline Proposed model & $2-20$ \\
\hline
\end{tabular}

implementation are however difficult to predict using the existing Matlab implementation. In particular, the data processing can be well adapted to parallel computing as, for instance, the different waves - forward and reverse, ground and aerial modes - can be computed separately. The implementation of the proposed approach to achieve computing times more in line with real-time applications remain nevertheless a challenge.

\section{CONCLUSION}

In this paper, the problem of the fast fault identification in meshed HVDC grids is addressed. A model of the first traveling waves generated by the fault is developed using a combined physical and behavioral approach. Modal analysis is applied to decouple the TW phenomenon and to represent the soil resistivity effects on the ground mode. The model depends explicitly on the fault parameters and is thus adjustable to any faults occurring on the protected line. When a fault is suspected, the estimation of the fault parameters allows to identify it as internal or external. Extensive simulations show that the proposed algorithm is able to selectively identify faults using a measurement window less than $0.5 \mathrm{~ms}$ long. Furthermore, the estimated fault distance and resistance provide insights on the severity of the fault and allow one to fine-tune the fault clearing and protection strategy triggered.

\section{REFERENCES}

[1] P. Fairley, "Germany jump-starts the supergrid," IEEE Spectrum, vol. 50, no. 5, pp. 36-41, 2013.

[2] D. Van Hertem and M. Ghandhari, "Multi-terminal VSC HVDC for the European supergrid: Obstacles," Renewable and Sustainable Energy Reviews, vol. 14, no. 9, pp. 3156-3163, 2010.
[3] D. Jovcic, G. Tang, and H. Pang, "Adopting Circuit Breakers for High-Voltage dc Networks: Appropriating the Vast Advantages of dc Transmission Grids," IEEE Power and Energy Magazine, vol. 17, no. 3, pp. 82-93, 2019.

[4] P. Verrax, A. Bertinato, M. Kieffer, and B. Raison, "A novel singleended fault identification algorithm for full selective protection strategy," in Proc. DPSP, Liverpool, 2020, pp. 1-6.

[5] K. Shinoda, A. Benchaib, J. Dai, and X. Guillaud, "Virtual Capacitor Control for Stability Improvement of HVDC System Comprising DC Reactors," in Proc. ACDC, Belfast, 2019, pp. 1-6.

[6] N. Tong, X. Lin, Y. Li, Z. Hu, N. Jin, F. Wei, and Z. Li, "Local Measurement-Based Ultra-High-Speed Main Protection for Long Distance VSC-MTDC," IEEE Transactions on Power Delivery, vol. 34, no. 1, pp. 353-364, 2019.

[7] A. Meghwani, S. C. Srivastava, and S. Chakrabarti, "Local measurementbased technique for estimating fault location in multi-source DC microgrids," IET Generation, Transmission and Distribution, vol. 12, no. 13, pp. 3305-3313, 2018.

[8] J. Suonan, J. Zhang, Z. Jiao, L. Yang, and G. Song, "Distance Protection for HVDC Transmission Lines Considering Frequency-Dependent Parameters," IEEE Transactions on Power Delivery, vol. 28, no. 2, pp. 723-732, 2013

[9] P. Verrax, A. Bertinato, M. Kieffer, and B. Raison, "Transient-based fault identification algorithm using parametric models for meshed HVDC grids," Electric Power Systems Research, vol. 185, no. April, p. 106387, 2020.

[10] J. Mahseredjian, S. Dennetière, L. Dubé, B. Khodabakhchian, and L. Gérin-Lajoie, "On a new approach for the simulation of transients in power systems," Electric Power Systems Research, vol. 77, no. 11, pp. $1514-1520,2007$.

[11] J. De Andrade Suárez and E. Sorrentino, "Typical expected values of the fault resistance in power systems," in Proc. IEEE/PES T\&D-LA, Sao Paulo, 2010, pp. 602-609.

[12] J. Sneath and A. D. Rajapakse, "Fault Detection and Interruption in an Earthed HVDC Grid Using ROCOV and Hybrid DC Breakers," IEEE Transactions on Power Delivery, vol. 31, no. 3, pp. 971-981, 2016.

[13] P. Torwelle, A. Bertinato, B. Raison, T. D. Le, and M. Petit, "Compliance of a Cable-Based Protection Strategy for Ohl Grids : Analysis and Remediation," in Proc. DPSP, IET, Ed., Liverpool, 2020, pp. 1-6.

[14] E. Walter and L. Pronzato, Identification of parametric models from experimental data. London: Springer-Verlag, 1997.

[15] G. A. Franklin, "Using modal analysis to estimate received signal levels for a power-line carrier channel on a $500-\mathrm{kV}$ transmission line," IEEE Transactions on Power Delivery, vol. 24, no. 4, pp. 2446-2454, 2009.

[16] W. Leterme and D. Van Hertem, "Reduced Modular Multilevel Converter Model to Evaluate Fault Transients in DC Grids," in Proc. DPSP, Copenhagen, 2014, pp. 1-6.

[17] E. W. Kimbark, "Transient Overvoltages Caused by Monopolar Ground Fault on Bipolar DC Line: Theory and Simulation," IEEE Transactions on Power Apparatus and Systems, vol. PAS-89, no. 4, pp. 584-592, 1970.

[18] A. Wasserrab and G. Balzer, "The significance of frequency-dependent overhead lines for the calculation of HVDC line short-circuit currents," Electrical Engineering, vol. 97, no. 3, pp. 213-223, 2015.

[19] M. Haeusler and S. Biswas, "HVDC Solutions for Integration of the Renewable Energy Resources Comparison of Technical Alternatives and System Configurations," in Proc. 1st International Conference on LargeScale Grid Integration of Renewable Energy in India, 2017, pp. 1-5.

[20] CIGRE WG B2/B4/C1.17, "Impacts of HVDC lines in the economics of HVDC projects," CIGRE, Tech. Rep. 388, 2009.

[21] H. Saad, S. Dennetiere, J. Mahseredjian, P. Delarue, X. Guillaud, J. Peralta, and S. Nguefeu, "Modular multilevel converter models for electromagnetic transients," IEEE Transactions on Power Delivery, vol. 29, no. 3, pp. 1481-1489, 2014.

[22] C. Zhang, G. Song, T. Wang, L. Wu, and L. Yang, "Non-unit Traveling Wave Protection of HVDC Grids Using Levenberg-Marquart Optimal Approximation," IEEE Transactions on Power Delivery, vol. PP, no. c, pp. $1-1,2020$.

[23] T. Fawcett, "An introduction to ROC analysis," Pattern Recognition Letters, vol. 27, no. 8, pp. 861-874, 2006.

[24] J. Guo, G. Wang, Y. Liang, and D. Zeng, "Global-Sensitivity-Based Theoretical Analysis and Fast Prediction of Traveling Waves with Respect to Fault Resistance on HVDC Transmission Lines," IEEE Transactions on Power Delivery, vol. 30, no. 4, pp. 2007-2016, 2015. 